Kansas State University Libraries

New Prairie Press

\title{
DETECTING FACTORS ASSOCIATED WITH SPRINGWHEAT YIELD STABILITY IN SOUTH DAKOTA ENVIRONMENTS
}

Jixiang $\mathrm{Wu}$

Karl Glover

William Berzonsky

Follow this and additional works at: https://newprairiepress.org/agstatconference

Part of the Agriculture Commons, and the Applied Statistics Commons

\section{(c) (1) $\Theta$}

This work is licensed under a Creative Commons Attribution-Noncommercial-No Derivative Works 4.0 License.

\section{Recommended Citation}

Wu, Jixiang; Glover, Karl; and Berzonsky, William (2013). "DETECTING FACTORS ASSOCIATED WITH SPRINGWHEAT YIELD STABILITY IN SOUTH DAKOTA ENVIRONMENTS," Conference on Applied Statistics in Agriculture. https://doi.org/10.4148/2475-7772.1021

This is brought to you for free and open access by the Conferences at New Prairie Press. It has been accepted for inclusion in Conference on Applied Statistics in Agriculture by an authorized administrator of New Prairie Press. For more information, please contact cads@k-state.edu. 
Detecting Factors Associated with Spring Wheat Yield Stability in South Dakota Environments

\author{
Jixiang $\mathrm{Wu}^{*}$, Karl Glover, and William Berzonsky \\ Plant Science Department, South Dakota State University, Brookings, SD 57007 \\ *Contact author: Jixiang.wu@sdstate.edu
}

\begin{abstract}
Conventional yield stability analyses are focused on yield stability itself by using single linear regression method and/or additive main effect and multiplicative interaction (AMMI) analysis. It is likely that yield stability for a genotype is associated with many factors such as fertilizer level, soil types, weather conditions, and/or yield components. Detection of factors highly associated with yield stability, therefore, will help breeders develop cultivars adapted to diverse environments or to specific environments. In this study, we conducted correlation analysis based on both environments and genotypes for a data set with 22 spring wheat genotypes, which were evaluated in 18 environments (combinations of years and locations) in South Dakota from 2009 to 2011. In addition, a multiple linear regression method was used to detect the associations of three agronomic traits with yield stability. The results showed that yield had diverse correlations each of three traits among different environments, indicating the importance of these three traits varied among environments. Our results also showed that plant height played a consistent important role on spring wheat yield production while the other two traits played less frequent role on yield production based on multiple linear regression analyses.
\end{abstract}

\title{
1. Introduction
}

Wheat is the principal cereal grain gown in the United States, ranking the fourth in production and the first in export. North plain including Minnesota, North Dakota, and South Dakota is the leading producer of wheat crops. As the world population continues to increase, scientists are facing a difficult dilemma - meeting increasing food requirements with decreasing land availability. On the other hand, domestic demand is also increasing because more wheat is needed for animal and human feed to replace corn being grown to make fuel. Therefore, improving wheat production and quality has become a more urgent goal for scientists in this area.

Genotype-by-environment $(\mathrm{G} \times \mathrm{E})$ interactions are a common and critical issue in developing widely adapted crop cultivars (Gray, 1982; Kang \& Miller, 1984). It is hard to predict yield performance in untested environments for genotypes when high $\mathrm{G} \times \mathrm{E}$ interactions exist because these genotypes have low performance stability. Crop trials or crop performance tests (CPT) at multiple locations and possibly in multiple years are often executed to generate experimental data for measuring yield stability of a genotype. Due to various definitions of yield stability (Lin, Binns, \& Lefkovitch, 1986), different statistical methods for measuring stability have been proposed. Based on the review paper (Lin et al.,1986), these methods can be clustered 
into two basic categories: variation-based (Francis \& Kannenberg, 1978; Plaisted \& Peterson, 1959; Shukla, 1972; Wricke, 1962) and regression-based (Eberhart \& Russell, 1966; Finlay \& Wilkinson, 1963; Perkins \& Jinks, 1968). Another commonly used approach is the additive main effects and multiplicative interaction (AMMI) method (Crossa, Gauch, \& Zobel, 1990). The AMMI method is a principal component analysis based approach.

A large number of publications can be found in literature regarding $\mathrm{G} \times \mathrm{E}$ interactions in both winter and springs wheat crops (Acciaresi \& Chidichimo, 1999; Acuna \& Wade, 2012; Castillo, Matus, del Pozo, Madariaga, \& Mellado, 2012; Sivapalan et al., 2000) . Yield stability analysis for wheat based regression method or AMMI methods was widely reported (Haile, Sarial, \& Assefa, 2007; Ilker et al., 2011; Madry, Gacek, Paderewski, Gozdowski, \& Drzazga, 2011; Silva et al., 2011; Sivapalan et al., 2000; Ulker, Sonmez, Ciftci, Yilmaz, \& Apak, 2006). However, above mentioned studies were more focused on yield stability analysis for a genotype across environments. Many studies have shown that crop yield consists of several yield components, which could directly or indirectly impact yield. Genetic studies in wheat revealed that agronomic traits including yield components were associated with grain yield (Li, Yan, Wei, Lan, \& Zheng, 2006; Motzo, Giunta, \& Deidda, 2001; Wu, Chang, \& Jing, 2012). Thus, it is important to investigate associations of agronomic traits with wheat yield production thus yield stability.

In this study, a spring wheat data set including 22 cultivars grown in 18 environments (combinations of three years and six locations) in South Dakota Environments was analyzed. Environment-wide and genotype-wide correlations between yield and testing weight, heading date and plant height were estimated and statistically tested. In addition, multiple linear regression analyses were conducted to reveal the associations of three agronomic traits with spring wheat yield for each of 22 genotypes. The results will provide useful information on selecting spring wheat cultivars appropriately in South Dakota environments

\section{Materials and Statistical Methods \\ 2.1.Materials}

The data used in this study came from South Dakota State University spring wheat advanced yield test (AYT) during 2009 and 2011. Six locations, Aurora (AUR), Brookings (BRK), Groton (GRO), Redfield (RED), Selby (SEL), and Watertown (WAT) were used as advanced yield test locations. There were total 18 environments (combinations of six locations and three years) (Table 1). There were total 74 genotypes were tested in three years; however, only 22 genotypes (please refer to Table 2) were grown in all 18 environments. A randomized complete block design with three replications was used in each environment and standard field practices were followed during the growing seasons. Grain yield, testing weight (TW), heading date (HD), and plant height $(\mathrm{PH})$ were recorded for each field plot. Without losing the focuses of this study, only the balanced data, which included 22 genotypes and 18 environments, were used to investigate factors associated with yield stability.

\subsection{Statistical methods}

Pearson's correlations between yield and three agronomic traits, testing weight, heading date, and plant height under with each environment (environment-wide correlations) and for each genotype across 18 environments (genotype-wide correlations) were calculated. In order to determine particular agronomic traits associated with yield stability, multiple linear regression 
models were employed for yield on three agronomic traits from 18 environments for each of 22 genotypes. For comparison, single linear regression analysis based on environmental index (Finlay \& Wilkinson, 1963) was used to determine grain yield stability for these 22 spring wheat genotypes. All correlation analyses and regression analyses were based on mean values from each environment. All data analyses were conducted by R programs that were developed by the authors of this study.

\section{Results \& Discussion}

\subsection{Correlation analysis between spring wheat yield and three agronomic traits}

We conducted two types of correlation analyses for grain yield and other three agronomic traits: environment-wide and genotype-wide correlations. The environment-wide correlations, which were based on correlation analysis between mean yield and three agronomic traits within each environment, could reveal the impacts of traits on yield production, while genotype-wide correlations, which were based on correlation analysis for each of 22 genotypes, could reveal which traits playing important roles on yield production between mean yield and three agronomic traits for a particular genotype across these environments. The results are presented in Tables 1 and 2, respectively.

The correlations between yield and testing weight (TW) ranged from -0.23 (Brookings in 2009, 2010:BRK) to 0.91 (GRO, 2011, 2011:GRO) across 18 environments with mean correlation of 0.27 (Table 1). The correlations between yield and heading date ranged from 0.95(Brookings in 2010, 2010:BRK) to 0.69 (Selby in 2010, 2010:SEL) across environments with mean -0.18 . The correlations between yield and plant height ranged from -0.66 (Watertown in 2009, 2009:AUR) to 0.89 (RED in 2010, 2010:RED) with mean 0.31. The results clearly showed that agronomic traits impacted spring wheat yield production differently across these 18 environments, indicating that different agronomic traits may be considered to maximize spring wheat yield production in specific environment.

Compared to environment-wide correlations between yield and three agronomic traits, the correlations between yield and these three traits were more consistent among genotypes (Table 2). Numerically, yield had positive correlations with testing weight and plant height while negative correlations with heading date across all 18 environments. Yield had correlations with testing weight ranging from 0.36 (GRANGER) to 0.82 (SD 3997) with mean 0.60, heading date ranging from -0.57 (OXEN) to -0.25 (STEELE-ND) with mean -0.42, and plant height ranging from 0.33 (REEDER) to 0.66 (STEELE-ND). These results suggested that these testing spring wheat genotypes may show similar yield stability.

In summary, our correlation analyses showed that spring wheat grain yield had correlation each of these three agronomic traits with different patterns among environments yet similar patterns among genotypes. Significant correlations between yield and these agronomic traits revealed that yield product are dependent on the performances of other traits, thus consequently, yield stability may be also associated with these agronomic traits. Thus, we employed multiple linear regression models to determine the factors associated with yield production for each genotype, as further detailed in the study.

\subsection{Multiple linear regression for yield with three agronomic traits}

Correlations between yield and three agronomic traits were significant for most genotypes as indicated in our genotype-wide correlation analyses (Table 2) and correlations patterns were different among different environments (Table 1). These were some evidences that 
grain yield is not only affected by these traits. Therefore, it is reasonable to hypothesize that yield stability of a genotype may be also associated with one or more agronomic traits. In order to reveal the yield stability of genotype associated with other traits appropriately, we conducted multiple linear regression analyses using mean yield values of each genotype at different environments (considered as responsible variable y) and the corresponding mean values of the other three traits at different environments (considered as independent variables $\mathrm{X}$ ). Intercept (b0), slopes for three agronomic traits, and adjusted coefficient of determination $R_{M L R}^{2}$ for each genotype are provided in columns 1 to 5 of Table 3. For comparison, the adjusted coefficient of determination $\left(R_{F W}^{2}\right)$ based on environmental index (Finlay \& Wilkinson, 1963) for each genotype is also provided (columns 6 of Table 3 ).

Plant height played a positive and significant role on spring wheat yield for six genotypes (columns 4, Table 3). Testing weight showed positive and significant role on yield for nine genotypes (column 2) while heading date played no significant role on yield for these genotypes (column 3). At least two agronomic traits significantly impacted yield for each genotype (Table 3 ). These results were consistent with our genotype-wide correlation analyses reported in Table 2 in this study.

Results in Table 3 showed that these genotypes had high $R_{F W}^{2}$ (numerically greater than 0.90 ), showing similar yield stability based on these testing environments. The major reason was that environmental effects played a primary role on yield (87\%). Adjusted coefficients of determination $R_{M L R}^{2}$ ranged from 0.25 (SD4165) to 0.68 (STEELE-ND) with mean 0.42 among 22 genotypes. The results indicated that these three traits could contribute from $25 \%$ to $55 \%$ to the total variation in yield. The ratio of $R_{M L R}^{2} / R_{F W}^{2}$ can be considered as an index that the contribution rate from these three agronomic traits to yield stability for each genotype. Our results showed that three traits could contribute 29 to $70 \%$ to yield stability in these 18 environments.

On summary, our results showed that correlation patterns for spring wheat yield and three agronomic traits were different among environmental conditions (Table 1); however, they were similar among different genotypes (Table 2). In this study, we employed multiple linear regression analyses by three agronomic traits as independent variables rather than environmental index (Finlay \& Wilkinson, 1963) commonly used in many studies. Such analyses helped determine which agronomic traits significantly contributed yield product include yield stability for each genotype. Our results showed that three traits made a large contribution to yield for each genotype and the impacts of these three agronomic traits were different among these testing genotypes (Table 3).

\section{References}

Acciaresi, H. A., \& Chidichimo, H. O. (1999). Genotype environment interactions in wheat in the IV and Vsouth Argentinean subregions. Cereal Research Communications, 27(1-2), 115-122.

Acuna, T. L. B., \& Wade, L. J. (2012). Genotype x environment interactions for root depth of wheat. Field Crops Research, 137, 117-125. doi: DOI 10.1016/j.fcr.2012.08.004

Castillo, D., Matus, I., del Pozo, A., Madariaga, R., \& Mellado, M. (2012). ADAPTABILITY AND GENOTYPE x ENVIRONMENT INTERACTION OF SPRING WHEAT CULTIVARS IN CHILE USING REGRESSION ANALYSIS, AMMI, AND SREG. Chilean Journal of Agricultural Research, 72(2), 167-174.

Crossa, J., Gauch, H. G., \& Zobel, R. W. (1990). Additive Main Effects and Multiplicative Interaction Analysis of Two International Maize Cultivar Trials. Crop Science, 30(3), 493-500. 
Eberhart, S. A., \& Russell, W. A. (1966). Stability parameters for comparing verirties. Crop Science, 6, 3640.

Finlay, K. W., \& Wilkinson, G. N. (1963). The analysis of adaptation in a plant-breeding programme. Aust. J. Agric. Res., 14, 742-752.

Francis, T. R., \& Kannenberg, L. W. (1978). Yield stability studies in short season maize. I. A descriptive method for grouping genotypes. Can. J. Plant Sci., 58, 1029-1034.

Gray, E. (1982). Genotype $\times$ environment interactions and stability analysis for forage yield of orchardgrass clones. Crop Science, 22, 19-23.

Haile, J. K., Sarial, A. K., \& Assefa, S. (2007). AMMI analysis for stability and locations effect on grain protein content of durum wheat genotypes. Cereal Research Communications, 35(4), 1661-1673. doi: Doi 10.1556/Crc.35.2007.4.13

Ilker, E., Geren, H., Unsal, R., Sevim, I., Tonk, F. A., \& Tosun, M. (2011). Ammi-Biplot Analysis of Yield Performances of Bread Wheat Cultivars Grown at Different Locations. Turkish Journal of Field Crops, 16(1), 64-68.

Kang, M. S., \& Miller, J. D. (1984). Genotype x environment interactions for cane and sugar yield and their implications in sugar breeding. Crop Science, 24, 435-440.

Li, W., Yan, Z. H., Wei, Y. M., Lan, X. J., \& Zheng, Y. L. (2006). Evaluation of genotype x environment interactions in chinese spring wheat by the AMMI model, correlation and path analysis. Journal of Agronomy and Crop Science, 192(3), 221-227. doi: DOI 10.1111/j.1439-037X.2006.00200.x

Lin, C. S., Binns, M. R., \& Lefkovitch, P. L. (1986). Stability analysis: where do we stand? Crop Science, 26, 894-899.

Madry, W., Gacek, E. S., Paderewski, J., Gozdowski, D., \& Drzazga, T. (2011). Adaptive yield response of winter wheat cultivars across environments in Poland using combined AMMI and cluster analyses. International Journal of Plant Production, 5(3), 299-309.

Motzo, R., Giunta, F., \& Deidda, M. (2001). Factors affecting the genotype x environment interaction in spring triticale grown in a Mediterranean environment. Euphytica, 121(3), 317-324. doi: Doi 10.1023/A:1012077701206

Perkins, J. M., \& Jinks, J. L. (1968). Environmental and genotype-environmental components of variability. III. Multiple lines and crosses. Heredity, 23, 18.

Plaisted, R. L., \& Peterson, L. C. (1959). A technique for evaluating the ability of selections to yield consistently in different locations or seasons. Amer. Potato J., 36, 381-385.

Shukla, C. K. (1972). Some statistical aspects of partitioning genotype-environmental components of variability. Heredity, 29, 237-245.

Silva, R. R., Benin, G., da Silva, G. O., Marchioro, V. S., de Almeida, J. L., \& Matei, G. (2011). Adaptability and stability of wheat cultivars at different sowing dates in the state of Parana, Brazil. Pesquisa Agropecuaria Brasileira, 46(11), 1439-1447.

Sivapalan, S., O'Brien, L., Ortiz-Ferrara, G., Hollamby, G. J., Barclay, I., \& Martin, P. J. (2000). An adaptation analysis of Australian and CIMMYT/ICARDA wheat germplasm in Australian production environments. Australian Journal of Agricultural Research, 51(7), 903-915. doi: Doi 10.1071/Ar99188

Ulker, M., Sonmez, F., Ciftci, V., Yilmaz, N., \& Apak, R. (2006). Adaptation and stability analysis in the selected lines of Tir wheat. Pakistan Journal of Botany, 38(4), 1177-1183.

Wricke, G. (1962). Uber eine Methode zur Erfassung der okologischen Streubreite in Feldversuchen. $Z$. Pflanzenzuchtg, 47, 92-96.

Wu, X. S., Chang, X. P., \& Jing, R. L. (2012). Genetic Insight into Yield-Associated Traits of Wheat Grown in Multiple Rain-Fed Environments. Plos One, 7(2). doi: ARTN e31249 DOI

10.1371/journal.pone.0031249 
Table 1. Correlations and the corresponding $\mathrm{P}$ values between spring wheat yield and three agronomic traits: testing weight (TW), heading date (HD), and plant height (PH) for each environment.

\begin{tabular}{lrrrrrr}
\hline & \multicolumn{3}{c}{ TW } & \multicolumn{3}{l}{ PH } \\
\cline { 2 - 7 } Environment & Estimate & P_value & Estimate & P_value & Estimate & P_value \\
\hline 2009:AUR & 0.452 & 0.035 & -0.643 & 0.001 & 0.508 & 0.016 \\
2009:BRK & -0.234 & 0.296 & -0.836 & 0.000 & 0.464 & 0.029 \\
2009:GRO & -0.119 & 0.599 & -0.113 & 0.617 & 0.231 & 0.301 \\
2009:RED & -0.129 & 0.568 & -0.618 & 0.002 & 0.474 & 0.026 \\
2009:SEL & 0.446 & 0.037 & 0.604 & 0.003 & 0.524 & 0.012 \\
2009:WAT & -0.067 & 0.766 & -0.073 & 0.746 & -0.661 & 0.001 \\
2010:AUR & -0.122 & 0.587 & 0.639 & 0.001 & 0.252 & 0.259 \\
2010:BRK & 0.567 & 0.006 & -0.951 & 0.000 & 0.759 & 0.000 \\
2010:GRO & 0.043 & 0.850 & -0.370 & 0.090 & 0.329 & 0.135 \\
2010:RED & 0.540 & 0.010 & 0.640 & 0.001 & 0.891 & 0.000 \\
2010:SEL & 0.634 & 0.002 & 0.689 & 0.000 & 0.778 & 0.000 \\
2010:WAT & 0.504 & 0.017 & -0.637 & 0.001 & -0.389 & 0.074 \\
2011:AUR & 0.466 & 0.029 & -0.766 & 0.000 & 0.806 & 0.000 \\
2011:BRK & 0.599 & 0.003 & -0.431 & 0.045 & 0.312 & 0.158 \\
2011:GRO & 0.908 & 0.000 & -0.489 & 0.021 & -0.077 & 0.734 \\
2011:RED & 0.351 & 0.109 & -0.143 & 0.525 & 0.031 & 0.891 \\
2011:SEL & 0.279 & 0.209 & -0.063 & 0.781 & -0.013 & 0.955 \\
2011:WAT & -0.208 & 0.354 & 0.327 & 0.138 & 0.305 & 0.168 \\
Min & -0.234 & & -0.951 & & -0.661 & \\
Max & 0.908 & & 0.689 & & 0.891 & \\
Mean & 0.273 & & -0.180 & & 0.307 & \\
\hline
\end{tabular}


Table 2. Correlations and the corresponding $\mathrm{P}$ values between spring wheat yield and three agronomic traits: testing weight (TW), heading date (HD), and plant height (PH) for each genotype.

\begin{tabular}{lrrrrrr}
\hline & \multicolumn{1}{l}{ TW } & \multicolumn{3}{l}{ HD } & \multicolumn{3}{l}{ PH } \\
\cline { 2 - 7 } Genotype & Estimate & P_value & Estimate & P_value & Estimate & P_value \\
\hline ALSEN & 0.552 & 0.017 & -0.490 & 0.039 & 0.493 & 0.038 \\
BRICK & 0.536 & 0.022 & -0.317 & 0.201 & 0.512 & 0.030 \\
BRIGGS & 0.575 & 0.013 & -0.427 & 0.077 & 0.537 & 0.022 \\
FALLER & 0.588 & 0.010 & -0.490 & 0.039 & 0.606 & 0.008 \\
GRANGER & 0.362 & 0.140 & -0.483 & 0.043 & 0.429 & 0.075 \\
KELBY & 0.542 & 0.020 & -0.440 & 0.068 & 0.487 & 0.040 \\
KNUDSON & 0.511 & 0.030 & -0.362 & 0.140 & 0.579 & 0.012 \\
OXEN & 0.483 & 0.042 & -0.565 & 0.015 & 0.590 & 0.010 \\
REEDER & 0.688 & 0.002 & -0.420 & 0.083 & 0.333 & 0.176 \\
RUSS & 0.662 & 0.003 & -0.476 & 0.046 & 0.542 & 0.020 \\
SD3997 & 0.816 & 0.000 & -0.338 & 0.170 & 0.429 & 0.076 \\
SD4023 & 0.629 & 0.005 & -0.385 & 0.115 & 0.560 & 0.016 \\
SD4076 & 0.750 & 0.000 & -0.439 & 0.068 & 0.564 & 0.015 \\
SD4112 & 0.608 & 0.007 & -0.341 & 0.165 & 0.622 & 0.006 \\
SD4165 & 0.507 & 0.032 & -0.309 & 0.211 & 0.414 & 0.088 \\
SD4178 & 0.560 & 0.016 & -0.318 & 0.198 & 0.593 & 0.009 \\
SD4181 & 0.395 & 0.105 & -0.488 & 0.040 & 0.363 & 0.139 \\
SD4189 & 0.628 & 0.005 & -0.443 & 0.065 & 0.557 & 0.016 \\
SD4199 & 0.583 & 0.011 & -0.349 & 0.156 & 0.444 & 0.065 \\
SELECT & 0.718 & 0.001 & -0.368 & 0.133 & 0.467 & 0.051 \\
STEELE-ND & 0.793 & 0.000 & -0.254 & 0.308 & 0.660 & 0.003 \\
TRAVERSE & 0.498 & 0.004 & -0.421 & 0.082 & 0.547 & 0.019 \\
Min & 0.362 & & -0.565 & & 0.333 & \\
Max & 0.816 & & -0.254 & & 0.660 & \\
Mean & 0.595 & & -0.405 & & 0.513 & \\
\hline & & & & & &
\end{tabular}


Table 3. Multiple linear regression analysis on yield with three agronomic traits

\begin{tabular}{lrrrrrl}
\hline Genotype & \multicolumn{1}{c}{$\mathrm{b} 0$} & $\mathrm{TW}$ & $\mathrm{HD}$ & $\mathrm{PH}$ & $R_{M L R}^{2}$ & $R_{F W}^{2}$ \\
\hline ALSEN & 110.550 & 1.201 & -1.136 & 0.750 & 0.366 & 0.958 \\
BRICK & -99.337 & 2.442 & -0.487 & $1.173^{*}$ & 0.357 & 0.961 \\
BRIGGS & 35.119 & 2.186 & -1.043 & 0.905 & 0.367 & 0.976 \\
FALLER & 42.491 & 0.708 & -0.869 & 1.304 & 0.384 & 0.929 \\
GRANGER & 119.572 & 1.086 & -1.178 & 0.756 & 0.292 & 0.919 \\
KELBY & -56.323 & 2.653 & -0.752 & 0.984 & 0.297 & 0.958 \\
KNUDSON & -54.920 & 2.096 & -0.622 & $1.127^{*}$ & 0.394 & 0.977 \\
OXEN & 142.773 & 1.209 & -1.465 & $1.032^{*}$ & 0.463 & 0.928 \\
REEDER & -312.827 & $5.161^{*}$ & 0.522 & -0.363 & 0.376 & 0.947 \\
RUSS & -88.298 & $2.382^{*}$ & -0.459 & 0.875 & 0.454 & 0.977 \\
SD3997 & -301.407 & $4.648^{* *}$ & 0.571 & 0.026 & 0.612 & 0.954 \\
SD4023 & -234.358 & $2.912^{*}$ & 0.133 & 0.994 & 0.432 & 0.977 \\
SD4076 & -284.817 & $3.445^{* *}$ & 0.251 & 1.029 & 0.571 & 0.949 \\
SD4112 & -224.291 & $3.078^{*}$ & 0.031 & $0.922^{*}$ & 0.485 & 0.990 \\
SD4165 & -119.560 & 2.694 & -0.361 & 0.926 & 0.252 & 0.958 \\
SD4178 & -174.407 & 2.919 & -0.280 & $1.200^{*}$ & 0.475 & 0.949 \\
SD4181 & 83.752 & 1.564 & -1.128 & 0.782 & 0.264 & 0.905 \\
SD4189 & -146.300 & $2.757^{*}$ & -0.417 & $1.319^{*}$ & 0.510 & 0.939 \\
SD4199 & -141.217 & 2.853 & -0.228 & 0.799 & 0.322 & 0.929 \\
SELECT & -202.097 & $2.859^{*}$ & 0.181 & 0.520 & 0.473 & 0.958 \\
STEELE-ND & $-324.658^{*}$ & $3.440^{* *}$ & 0.498 & 0.982 & 0.675 & 0.963 \\
TRAVERSE & 39.867 & 1.066 & -0.799 & 0.985 & 0.328 & 0.969 \\
\hline
\end{tabular}

TW=testing weight, $\mathrm{HD}=$ heading date, and $\mathrm{PH}=$ plant height. 